\title{
The Need for a New Paradigm in Scandinavian Health Economics
}

\author{
GAVIN MOONEY ${ }^{1}$ \\ GUSTAV TINGHÖG ${ }^{2,3, *}$ \\ ALMINA KALKAN ${ }^{3}$ \\ ${ }^{1}$ Institute of Public Health, Research Unit of Health Economics, University of Southern Denmark, Denmark \\ ${ }^{2}$ Division of Economics, Department of Management and Engineering, Linköping University, Sweden \\ ${ }^{3}$ Division of Health Care Analysis, Department of Medical and Health Sciences, Linköping University, Sweden
}

\begin{abstract}
This paper argues that the discipline of health economics has lost its way due to its persistent focus on individualistic and consequential values. The paper suggests how this might be remedied in both theory and practice. It proposes a new paradigm for health economics, which focuses on communitarian values. This new paradigm is discussed in the context of the Scandinavian welfare model.
\end{abstract}

\section{Introduction}

The discipline of health economics early on acknowledged that health and health care are fundamentally different from most other commodities. Most health economists have therefore abandoned the idea of strict reliance on market forces as a mechanism to allocate health care either efficiently or equitably. Health economists have however not found and done all too little even to seek a suitable, reasonably comprehensive replacement. This paper suggests how this might be remedied in both theory and practice by proposing a new paradigm for health economics, which focuses on communitarian values. We argue for a rethink of what the future role and philosophy of health economics might be and here we concentrate on what this might mean in a Scandinavian context. The new paradigm is not a proxy for the market, but one in which the socially defined good of health care forms the basis of health care policy and which can more readily provide a value base for analysing the social determinants of health.

In doing so we place this paper in the domain of political economy. Issues of power, political contestation and inequality while not necessarily explicitly part of our argument nonetheless underpin it as they do our proposed paradigm.

The classical utilitarian normative claim underpinning welfare economics is that an act is justified if, and only if, it maximizes the overall good in society. Sen (1987) who is a major critic of the normative neoclassical framework, argues that the utilitarian ethical theory requires a combination of three elements.

i. Welfarism, which requires that goodness of a state of affairs be a function only of the utility information regarding that state.

ii. Maximization, which requires that utility information regarding any state be assessed by looking only at the sum of all the utilities in that state.

iii. Consequentialism, which requires that judgment regarding choices and actions be determined solely on the basis of the goodness of the consequent state of affairs. 
To these we would add:

iv. Individual consumer sovereignty, which does not allow for community or social preferences (except as the sum of individual preferences).

Hurley (1998, p. 375) argues that welfarism is 'the framework for normative economic analysis that has developed within the neo classical tradition'. Maximisation is then taken to be the maximisation of individuals' utilities and in turn consequentialism limits the bearing of utility to outcomes with the result that what might otherwise be deemed "process utility" does not exist. While it might be argued that it is already present in the three elements that Sen suggests are necessary for the neoclassical framework, because it is so central to our concerns here, we have added 'individual consumer sovereignty' since this emphasises in the very explicit way we would wish that in welfarism there is a reliance on the maximisation of individuals' utilities. That particular reliance is where our challenge starts since it is clear that there can be a separation of values from desires as Sen (1992) makes clear.

Others too have expressed concerns for various aspects of current health economics - see for example Richardson (2001), Coast (2004) and Anand (2005) - but in the main, health economists have attempted little more than to patch things up. Health economists have been slow to accept the problems associated with contingent valuation (willingness-to-pay) in health care (but see Olsen 1997) while their colleagues in environmental economics have been much more ready to express their concerns (Ecosystem Valuation n.d. and Spash 2008). They have hung on to elements of welfarism in a way that seeks to keep, if not the market alive in health care, at least to try to maintain some of the principles underlying neoclassicism. An example is the measurement of 'moral hazard' which requires inter alia a conventional neoclassical demand curve to have any meaning. There is in health economics too little recognition that the maximand of welfarism (conventional utility) is inadequate (Sen 1992). Yet patients cannot maximise utility in the conventional sense as they are not adequately informed to do so and their values are formed by the process of illness and health care consumption and as such are not stable. The agency relationship has been called upon to overcome this problem but has been devalued as there is no agreement in the health economics literature as to what its precise function is. (For a review see Mooney and Ryan 1993.) Equity has been largely ignored. It has been neglected almost totally at a societal level. This is despite the evidence that the social determinants of health matter and that these in turn equate in the main to poverty and inequality. Further the implications of the separation of what is in the "evaluative space" (Sen 1992) for efficiency and what is there for equity have not been adequately addressed in health economics.

Extra welfarism is relatively new to health economics dating back only to the early 1990s (Culyer 1990). According to Hurley (1998 p 375) it 'refers to frameworks for normative economic analysis that reject the conceptual foundations of the neo-classical welfare framework, particularly the exclusive focus on utility-based notions of welfare'. This paper highlights the problems in conventional health economics in restricting itself to using the values of individuals qua individuals and in being consequentialist, both of these restrictions being true of welfarism as well as extra welfarism. There has been no real attempt to date (beyond that by Mooney 2009) to provide a comprehensive alternative health economics paradigm in the wake of market failure.

Within extra welfarism, health economists have invented QALYs (although the latter pre-date the former). The approach of extra welfarism - it is too limited to be called 
a paradigm - serves to make the task of health economists easier by moving what is in the proposed maximand from utility to health. That narrow consequentialism would undoubtedly be useful in a world where all that patients wanted from health care was health but beyond speculation (see for example Culyer 1988) there is no evidence that we have been able to find in the literature to support that contention and some, certainly with respect to citizens' values, to oppose it (Mooney 2010).

Health economists increasingly accept that what is in the evaluative spaces for efficiency and for equity differ but the implications of this in a world that is interpreted as consequentialist and dominated by the values of individuals qua individuals have been largely uninvestigated by health economists. With respect to efficiency there has been an emphasis through cost utility analysis on health in the evaluative space while equity analyses have focused more on use, sometimes access but seldom health. The question of how to deal with the different contents of the evaluative spaces needs to be addressed. The territory for health economics research has been very much on health care and little on health. As a result the social determinants of health are seriously under investigated by health economists.

Health economics has also been very micro focused. Clinical issues have dominated especially in economic evaluation where in more recent years with the advent of QALYs, cost utility analysis has often supplanted cost benefit analysis. There has been little research, certainly outside the developing world (although see Navarro 2002 and 2007) on more macro issues. Indeed it is easy to argue that currently there is little macro economic theory of health economics. The WHO Macroeconomic Commission on Health (2001) might seem an exception yet it was severely constrained in its scope and in turn findings as it chose to ignore ideological issues in its assessment of such macro issues. (For a critique see Katz 2007.)

Extra welfarism has thus further cornered health economists into valuing health through QALY maximization which, while clearly important, has left health economics looking decidedly a technocratic discipline somewhat divorced from the planning and decision aiding roles that might be expected of it. Even at the more technical level of economic evaluation, it has moved the discipline from the social framework of cost benefit analysis (which strictly is social cost social benefit analysis) to the more constrained non-social technique of cost utility analysis. In doing so much has been lost with respect to what is to be included - now too often restricted to health on the benefit side and health care resources on the cost side - and nothing gained with respect to who is doing the valuing - still assumed to be the individual. Hence, health economics is still a consequentialist discipline, valuing only outcomes and disregarding processes. Further the individual qua individual - the patient - and interventions aimed at the patient - are the focus. Health economics currently pays little attention to wider social concerns such as the social value of the health care system as an institution.

This has left something of a vacuum in health economics. It is for these reasons that we want to suggest that a new health economics paradigm is needed.

\section{Why is a new paradigm for health economics needed?}

One of us (GM) has previously argued for a need to shift the basis of health economics away from its current consequentialist and individual values base to one where the community takes on a key role in valuing not just outcomes but also processes. In particular this basis emphasises the social processes surrounding the creation of health. Hence the focus is on communitarianism (Mooney 2009), using in turn 'communitarian 
claims' to build a set of principles (or a 'constitution' to use Vanberg's (1994) expression) on which to build a new paradigm.

The notion of community is much debated and defined (see e.g. McMillan and Chavis 1986, Gusfield 1975). Most commonly it can be interpreted in a geographical sense or a psychological sense. The psychological sense of community has to do with a sense of togetherness as shared ends are sought. Hence, this notion of community does not necessarily have to be linked to locality and individuals typically belong to more than one community at one time, e.g. racial, ethnic, cultural, women or by age. With regards to health care however, most health service systems are for geographical areas - nations or regions or towns - so that here, in most instances, we are thinking of a community as a geographical entity. But it is nevertheless important to acknowledge the psychological sense of community.

This new community oriented way, this shift in thinking, is needed for two reasons. First we argue that the individualistic and consequentialist value base of health economics (as in both welfarism and extra welfarism and indeed health policy more generally) misses out on the idea of health care systems as social institutions rather than simply medical or even health care organisations. Bringing the community to the fore in terms of recognising that health services are there for the population they serve - not just people as patients - is the key thrust. Citizens value health, health care and health care systems and the last they do as social institutions at all times and not just when they are in receipt of services as patients. This means ensuring that the community qua community is brought into the decision making process not as some undifferentiated entity but nonetheless able to reach a consensus as a community with respect to such matters as the principles and priorities to underpin health care systems (Mooney 2010). This is the essence of communitarianism which values community participation as a process as well as valuing outcomes as perceived by and as valued by the community.

Second, the value principles of health economics which as indicated are under both welfarism and extra welfarism based on the idea of individuals maximising their own interests, either their utility or their health, ignore any notion of a wish to promote or even maximize community goals or interests. Thus missing is a concern for the community good (but see for example Margolis 1982). It follows that in current health economics the social good of equity struggles to be based on anything other than individuals having some sort of concern for other individuals. In this it is assumed that my individual utility is reduced because certain individuals I know of are in poor health - the so-called 'caring externality'. The fact that there are people in poor health (or disadvantaged in other ways) in the society of which we are members, and this is seen as being a bad feature of that society, does not in health economics currently count. This element of valuing the community as a community and wanting it to be a decent community is missing. Relevant here is that Wilkinson (2005 p 296) writes: 'it is important to recognize that our emotional ability to identify with each other is broadening, if not deepening. Where once people apparently felt quite unaffected by the suffering of any but their nearest and dearest, it looks as if the boundaries of our moral universe have been expanding: our tendency to identify with each other is slowly spreading from family to class, from class to nation, and now, for some at least, to most of the human race.'

We would agree. Our concern is that under health economics currently the extent to which people are allowed to be humane is quite limited. It is also the case that there is a continuing assumption from welfarism that there is a coincidence of values and desires. Yet for many poor and disadvantaged people who in the past may have had their expectations dashed this coincidence does not occur. Where they do not, only three avenues appear open in current health economics. First an attempt can be made to 
accommodate them in externalities but this is a deficient mechanism as it incorporates only the loss of utility suffered by the beholder and then only the beholder as an individual. Second it can be assumed that values are values and that the lack of coincidence with desires is ignored. Here is the worshipping at the altar of informed rational preferences so beloved by the neoclassicists and which ignores the fact that when desires and values are not coincident there cannot be rational preferences. Third a merit goods approach can be adopted and the values of these individuals replaced by ones which a rational individual whose values and desires would coincide would be assessed as having or holding. That amounts to a form of paternalism which we would rather avoid.

While each of these approaches can be used they are each deficient in failing to grapple with the fundamental concern expressed by Sen (1992) that some individuals 'have an inability to manage to desire adequately'. While Sen did not consider such disadvantaged people in the specific context of health, health care or health care systems, given the nature of these constructs, we argue that communitarian claims can allow such disadvantaged people to be acknowledged and have access to better health and health care.

One added concern we have with today's health economics is its assumption of universalism. Yet first health, second health care systems and third what constitute the social determinants of health (and their relative importance) are all to some degree culturally determined. Health is very clearly a cultural construct. For example Aboriginal people can see health as being not only holistic in the western sense and thus express concern at the 'body parts' approach - the separation of mind and body for example - to health but also bearing certain obligations (such that a son-in-law may have a responsibility to look after the health of a mother-in-law should she become sick). Health care systems vary in so far as different cultures want different things from their health care system. It is the cultural values of the Danes that result in their health care system being more concerned with equity than that of the US where equity is much less heavily weighted in that culture. What influences health socially is different in Swaziland from in Sweden so the social determinants of health vary culturally - and need to be defined by local communities.

\section{Communitarianism and communitarian claims - An alternative paradigm for health economics?}

The focus of communitarianism is the community. People are not just individuals but social beings and not as tends to be assumed in health economics free floating atoms. They are community animals with an identity influenced by the community in which they live and of which they are a part. They value the community and its institutions and value being part of that community and participating in the community. Crucially different here in comparison to both welfarism and extra welfarism is that individuals do not seek only to maximise their own individual utility or interests but also seek to maximise the community's interests. This is much akin to the 'dual' utility functions proposed by Margolis (1992). There he argued that people have two utility functions, one a standard selfish consequentialist function, and the other based on what he calls 'participation utility', where the utility is obtained not by the getting but by the doing, by participating in the community. Thus where this occurs community autonomy is strong and the society or community is based on such caring principles as reciprocity and community participation.

Further, Avineri and de-Shalit (1992 p 3) suggest that communitarians argue that 'to justify the special obligations that we hold to members of our communities - families, nations, and so forth - one must attach some intrinsic (i.e. non-instrumental) value to the community'. They suggest that, in comparison with individualistic theories, 
communitarianism 'better justifies obligations that are not universal but rather specific and particular, because these obligations are part of what constitutes the self'. Communitarianism has the advantage over current health economics of not seeking to be universal. It can accommodate different cultures and different cultural values.

It should be noted here, that communitarian attempts to define justice in terms of community values have been criticized for endorsing cultural relativism (see e.g Caney 1992, Rosa 1996), since particular communities and community values can be deeply regressive and repressive, not only of minorities but also of systematically disadvantaged majorities (e.g women). However, as Mooney (2010) writes: 'Communitarians are very much concerned with not only the shape of society but also the shaping of society. They do not believe that this can be left to individuals qua individuals.' This does not mean that within any community there will be no contestation of values but rather communitarianism recognizes the need to have that contestation. That in itself is in our view a major advantage.

Broome (1991 p 61) suggested that one way of grappling with questions of fairness was to argue that the reasons why someone should receive some good or service could be separated into two categories - "claims" and other reasons. The idea of a claim to a good meant that there was 'a duty owed to the candidate herself that she should have it.' Other reasons might include for example that the person already has it ("possession is nine tenths of the law") or it has been obtained by illegal means (and hence there is no duty that the person should have it). The duty might be owed by for example a spouse (the duty of faithfulness) or national government (the duty of national security). GM has previously argued for using this concept of claims to make it a basis for operationalising communitarianism. First "communitarian claims" are a sub-set of claims more generally. These communitarian claims rest with the community to address. Hence the duty with respect to communitarian claims is one that is owed by the community. It is the community who decide what constitute claims. They also determine the weights to be attached to these claims. Further the community sees value for themselves in arbitrating over claims.

Thus 'we the community determine how resources are allocated on the basis of how we the community determine first what constitute claims - what are deemed relevant criteria for allocating health care resources - and how we the community see various different groups' or individuals' strengths of claims for the resources involved. It is our preferences, the community's preferences, for their claims, the various groups' claims, that determine how the resources are allocated. It is we the community who also decide what is relevant in identifying and weighting claims in terms of the characteristics of the different potential recipient groups and the community as a whole' (Mooney and Russell 2003).

What might constitute claims and their weights will likely vary from community to community and from culture to culture. Prime candidates might include age, SES, ethnicity, timing and distribution, rural/urban, availability of alternatives, with dependents/without dependents, whether recipients are "contributors" or "drains" on society, etc. Thus some more traditional societies might see age as representing a claim to greater resources; more 'modern' societies might argue the reverse. A more market orientated society might see claims in terms of income representing a claim over resources. The weights attached to claims may also vary in the one society over time. The claim to health care resources for young men changed in the UK in the wake of the Boer War which led to a realisation that the army recruits for that war were rather frail. This was a part of the reason why the National Insurance Act of 1911 was introduced in essence recognising the then higher claims of such men to access health care (Gelbier and Randall 1982). 
Research is needed here to examine just what such claims might be and the weights that might be attached to them (but see Mooney 2010 for one example). The values of the community, the choosing of these values, and the eliciting of these values thus constitute the essence of the proposed communitarian paradigm.

\section{Communitarian Claims in Scandinavia}

It is generally agreed that the Scandinavian social insurance systems are more comprehensive than those of many other welfare states, and that they also share certain features, such as universalism, that means that they go further than many other countries' systems in reordering social relations and promoting high levels of social equality. What, more specifically, are the normative values that might constitute communitarian claims in the context of Scandinavian health and health care?

Ethical guidelines and principles for priority setting from the Scandinavian countries could be used as a departure for such explorations. In Sweden, the economic downturn of the early 1990s led to an explicit recognition that the need to ration care was inevitable. Significantly in the context of this paper it was also recognised that such rationing should involve community decisions that should be guided by community values. The idea was that openness and transparency would create legitimacy for implementing the inevitably politically difficult decisions that accompanied such recognition. This led to the formation of a commission on parliamentary priorities which was assigned to "consider the responsibilities of health and medical services, their demarcation and role in the welfare state; highlight fundamental ethical principles which can furnish guidance and form a basis of open discussions and of prioritization in health and medical services' (Ministry of Health and Social Affairs 1993). The communitarianism underpinnings of this task are clear, with the focus on bringing the community into the decision making process and in forming a basis of open discussions and prioritization in health services.

The Commission's work resulted in an ethical platform for setting priorities in health care (Ministry of health and social affairs Gov. bill 1996/97 p 60). This consisted of three principles intended to guide decision makers at all levels in the health care system when making rationing and priority-setting decisions. The principles were (and still are):

i. The principle of human dignity. Meaning that all individuals have equal value and rights regardless of personal characteristics or position in society.

ii. The principle of need and solidarity. Meaning that resources should be used in domains (or patients) where needs are considered to be greatest.

iii. The cost-efficiency principle. Meaning that resources should be used in the most effective way without neglecting fundamental duties to improve health and quality of life.

The principles are ordered lexicograhically in the sense that the human dignity principle has superiority over the need and solidarity principle, which in turn has superiority over the cost-efficiency principle. Following the Commission's work, the legislated goals of the Swedish healthcare system were amended. Prior to the Commission's report, the Swedish Health and Medical Service Act (1982 p 763 §2) stated that: 'the goal of all health care services is good health and health care on equal terms for the entire population'. The amendment which was added to this goal was: 'Provision of health care 
services must respect the equal value of all human beings, and the dignity of the single human being. The person with the greatest need for health care services should be given priority.' (Swedish Health and Medical Service Act 1997 p 142 2§). Here we see very explicitly the focus on people with the greatest needs (which might also be embodied within communitarian claims - as it has in an Australian exercise - Mooney 2010).

Norway undertook the first state initiative for exploring the value basis for priority setting in Scandinavia (Lönning Committee I and Lönning Committee II). As early as 1987 the Lönning I Committee discussed the following five principles for prioritising (Helse-og omsorgsdepartementet 1987): level of severity, equal opportunity for treatment, waiting time, economic aspects, and patients' self-responsibility. The Committee concluded that the severity level must be viewed as the most important principle in priority setting. The equity principle was to be interpreted to mean that health services should be offered in a way that everyone should be able to be as healthy as their circumstances allowed. Services should be available on the basis of being independent of social, geographical and age-related differences. Furthermore, the Committee concluded that it was important to develop more uniform criteria for administering waiting lists. The Committee also argued that economic considerations on their own were inadequate as a principle for setting priorities. Clearly resources need to be used efficiently but such a principle conflicts with a severity criterion. Finally, the Committee did not support the principle of giving lower priority to patients who were responsible for their own ill-health.

The Lönning II Committee in 1997 addressed primarily three principles for priority setting (Helse-og omsorgsdepartementet 1987): the severity level of the condition, expected benefits and cost-effectiveness, all of which the Committee found to be important. It argued that it was reasonable to treat first patients with serious diseases but that there was also a need to consider the expected benefits and the expected costs of treatment and hence they maintained that cost-effectiveness should also be a principle. The inquiry also discussed how to achieve some balancing of these principles but they did not establish an absolute ranking. Regarding the relationship between the severity principle and the benefit principle, they found that one cannot always prioritise patients with the poorest health despite a strong moralistic intuition to do so. The principle of costeffectiveness has to be balanced against that of fairness. As compared with Lönning I, the principles of benefit and cost-effectiveness were given higher weight in Lönning II. The latter was however less supportive of prioritising using age, lifestyle and health behaviour, productivity and social needs with these factors only to be considered under special circumstances and only at the clinical level.

In Denmark, an ethics council was established by the Danish parliament in 1987. The council's task was to discuss ethical issues that arise within the health sector. In 1996, this ethics council issued a report (Det Etiske råd 1996), which sets out what might be seen as claims but, given their source, not strictly communitarian claims, in a Danish context. At the outset, the ethics council argued against developing a Danish model of priority setting based on the Norwegian or Swedish initiatives. They state that it could be valuable to discuss the principles and criteria in these but argued that concrete decisions at the political, administrative and clinical levels should be based on a comprehensive assessment of many specific conditions. Certain core values, overriding health sector goals, and objectives aimed at operationalising the core values would have to be established as a basis for priority setting in the Danish health services. The ethics council argued for four core social values: equality of human worth, solidarity, security and safety, and freedom and self-determination. They described the overriding goal of the health sector as promoting health and preventing disease and thereby securing the potential for development of life among all citizens regardless of their social background and economic 
status. The report defined four important objectives: social and geographic equity, quality, cost-effectiveness, and democracy and user influence. A potential communitarian value from which the council distanced itself was that social status should influence priority setting, e.g. the unemployed, and those perceived to be responsible for their own ill-health.

\section{Health and health inequalities in Scandinavia}

As indicated in the preceding section, the key principle in the priority setting discussions in the Scandinavian countries has been the focus on equal value and rights of individuals, regardless of personal characteristics or position in society. This idea of social equality in health and health care can be traced to struggles such as labour movement and trade union campaigns that fought for such values and fundamentally contributed to the formation of the Scandinavian universal welfare model (Hilson 2008). The question that then needs to be asked is whether this focus on equality in health care and health has translated into better health in general and reduced inequality in health.

On the basis of current evidence in the literature, the answer does not seem to be straightforward. Several cross-country comparisons show that the Scandinavian countries rank better than other comparable developed countries on various population health measures (Marmot et al. 2010, Chung and Muntaner 2007, Navarro et al. 2006; Borrell et al. 2007). Cross-country comparisons of health outcomes primarily use EspingAndersen's (1990) original country classification of liberal / residual, conservative / corporatist / Bismarckian, and social democratic and some with Ferrera's (1996) addition of Southern regimes. In this classification the Scandinavian countries have typically been categorized as social democratic. Esping-Andersen`s (1990) typology in based on an analysis of three dimensions of welfare. First, social rights as measured by a "decommodification index" that captures the extent and generosity of key social security programmes (pensions, health and unemployment); second, the social stratification effects of welfare; and third, the public-private family welfare mix in the delivery of welfare. According to Esping-Andersen's analysis, liberal welfare state regimes are the most commodified, characterized by a strong emphasis on market-based mechanisms to support the needy - a status determined by means-testing. In the conservative ideal type, confidence on work-based insurance contributions results in status-dependant welfare benefits. This reflects a hierarchical social order with differing "decommodification" effects. The social democratic welfare regime displays the highest amount of relative social transfers. In this type, social policy targets the entire organisation of the societal infrastructure. It should however be noted that the Esping Andersen typologies of welfare systems have been subjected to critique. More specifically, it has proven difficult to distinguish the three typologies since most welfare states have components of all typologies in the system (Arts and Gelissen 2002). Others have pointed out that the Esping-Andersen typologies do not sufficiently take into account the gender inequality dimension in its attempt to classify welfare states (Siaroff 1994, Lewis 1997).

Social Democratic regimes appear to have a salutary effect on population health through the generous provision of universal welfare policies and labour market decommodification. This is shown for example in a recent literature review by Muntaner et al (2011) which is based on a political economy framework of health and welfare regimes, using Esping-Andersen typology for welfare state regimes. The authors located 73 empirical and comparative studies on politics and health. For population health differences across welfare state regimes there was a positive association between welfare generosity and better population health (19 studies, $61.3 \%$ ). 
While studies on the links between welfare type and population health levels all seem to point in the same direction - the welfare types of the Scandinavian countries seem to have a positive effect on population health levels - the findings for the links between welfare type and health inequalities are more ambiguous. Approximately a third of welfare state studies (11 studies, 35.5\%) found by Muntaner et al (2011) reported inconclusive associations of the effects of welfare type on reducing social class inequalities in health (Dahl et al. 2006, Muntaner et al. 2006) and gender and socioeconomic differences in health (Bambra et al. 2009).

Gerdtham and Johannesson (2000), estimate the survival and quality-adjusted survival in over 40,000 individuals from different income groups in Sweden, and show inequalities in health favoring the higher income groups. Burström et al. (2005) suggest further that the socio-economic inequality in health has increased between 1980 and 1997 in Sweden. Brønnum-Hansen and Baadsgaard (2007) report similarly a widening social gap in mortality in Denmark. Comparing with other countries, Mackenbach et al. (1997) were the first to show that although the Scandinavian countries have relatively low levels of economic inequality, they do not have correspondingly low levels of health inequality. They compared data on four indicators of self-reported morbidity by level of education, occupational class, and/or level of income for 11 countries, and years ranging from 1985 to 1992 . Sweden and Norway had larger relative inequalities in health than most other countries for both morbidity and mortality. This was confirmed in a study by Eikemo et al. (2008) that tested whether the magnitude of income-related health inequalities varied with welfare type in 23 European countries. They found that the Scandinavian countries ranked only in the middle vis-a-vis other highly developed European countries. Countries in liberal welfare states had the greatest health inequalities while countries in the conservative group (e.g., France, Germany, Italy) show the lowest socioeconomic differences in both mortality rates and self-reported measures of health.

Conversely, there are studies that point to the positive effects of the Scandinavian Welfare models on inequalities in population health (van Doorslaer et al. 1997, Kunst et al. 2005). For example, van Doorslaer et al. (1997) show that ill health in Sweden and Finland is less skewed towards low-income groups relative to other (OECD) countries. Kunst et al. (2005) comparing social health inequalities in 10 European countries, observe increasing inequalities for several of the countries apart from the Scandinavian ones. They suggest that Scandinavian welfare states were able to protect disadvantaged groups against many of the adverse health effects of economic crises.

Although the focus in the priority setting discussions has been on equal value and the rights of individuals, many studies still show high social inequalities in health in Scandinavia. Whether these inequalities are higher than in other comparable countries, regardless of the Scandinavian focus on decreasing them, is an interesting question for health economists to be involved in addressing. Another important and related question is how to implement changes that create better health for the whole population.

\section{A future agenda for Scandinavian health economists}

It is clear from the formulated ethical guidelines and principles for priority setting, as set out above, that the Scandinavian countries share many communitarian values in the often stated 'Scandinavian solidarity'. In all countries equity and solidarity are key values for priority setting. Still, the interpretation of these principles is less than clear, as is the extent to which these principles actually influence decisions in health and health care. Moreover, the current political rightwing shift in Scandinavia arguably challenges some of the egalitarian and participatory values by promoting more individualistic ones. What is more 
certain is that health economists in Scandinavia have devoted little time and effort to exploring the meaning and application of such principles. Their focus has been very much on the principle of efficiency. If health economists in Scandinavia are to make major advances in their efforts to try to ensure that scarce resources to further health and health related goals are used well, they need to increase their focus on issues around health and health care inequalities. In doing so it may transpire that the most efficient way to reduce health inequalities is to focus less on health care per se and more on wider public policy solutions - in essence on the social determinants of health. More research is needed on what the social and cultural environment of Scandinavia means for health inequalities but also what the social goals of inequalities in health and healthcare are and ought to be.

In comparison to most others, the Scandinavian countries have all clearly attempted to have more transparent priority setting processes that involve to some limited extent a communitarian approach, with at least something of a focus on bringing the community into the decision making process to form a basis for discussing and prioritizing health services. As of now it is unclear what impact these communitarian initiatives have had on overall wellbeing in the Scandinavian countries. It might well be postulated that it will have been positive but we need to know. It is clear to us that this issue needs to be higher on the agenda of health economists in Scandinavia.

The Swedish human dignity principle, which corresponds to the equal treatment principles in Denmark and Norway, argues that we should not consider personal characteristics such as talent, age, or gender - nor should we consider economic capacity or function in society, e.g. social position or social responsibility. When resources are scarce, it is impossible to adhere strictly to the standard that everyone has equal rights since everyone cannot have their needs fully met. That we have argued can be overcome by adopting a paradigm based on communitarian claims which recognises resource scarcity, that some claims are greater than others and that it is for the community to determine what constitute claims and the weights to be attached to them.

To address these issues, it is important to set out the principles on which health and the health care system are to be based. In a communitarian value based system we propose that these principles should be based on the preferences of a critically informed community. Scandinavian health economists need to take an active part in the debate on what these principles are to be and advocate in particular that the critically informed citizens are able to express their preferences and that in turn these are acted on.

The Swedish needs principle, and the Norwegian severity principle, indicate that those who are worst off should be prioritized but this says nothing about the extent to which they should be prioritized. When is the one worst off person to be prioritized before the one hundred on the second bottom rung? There needs to some weighting of "degrees of worseness" and this is where the weighting of claims comes in. Claims also allow judgments on what constitute the components of "worseness" (or disadvantage). Is it simply ill-health or are other criteria relevant, such as poverty or ethnicity or remoteness geographically?

This brings us to our final point, that political economy aspects of health economics should be increasingly a focus for health economists. Lying behind the thinking of this whole paper is a recognition that what is needed and currently ignored in most health economics is to examine the power base of health policy. Too often the deployment of resources in health care and of those which might foster the social determinants of heath are determined by some small undemocratic groupings. Arguing as we have done that health care is a social institution and population health a social matter is crucial in our thinking regarding such resource allocation both in health care systems and in those decisions at a more society level that impact on the social determinants of health. 
Yet these 'political economy' considerations are too seldom on health economists' agendas. Moreover, accepting this social perspective suggests in turn the need for the principles underpinning these issues to be defined by and valued by the critically informed community. It also implies that these are likely to vary according to different relevant cultural values.

There is no reason to believe that what Norwegians want from their health care system will be what Namibians want. What constitute the social determinants of health in Brazil may not apply in Belgium. In looking at inequalities, income inequalities, which are used in western countries to reflect power relations, might be poor proxies for such power relations in Africa, where these are often based on past colonial experiences. These issues are not ones that have much traction in current health economics. We argue this needs to change. There needs to be some new way of addressing in health economics the value bases or principles on which to operate when these social and cultural issues arise. We have suggested one for debate in this paper. Scandinavian health economists may agree or want to propose other remedies. There does seem to be a need to rethink the current paradigm.

Let the debate proceed!

\section{Acknowledgement}

We are most grateful for some truly insightful comments from an anonymous reviewer, which have helped us to improve the paper.

* Correspondence to: Gustav Tinghög, Linköping University, Sweden. E-mail: gustav.tinghog@liu.se 


\section{References}

Anand P (2003) The integration of claims to health care. Journal of Health Economics 22 731-45.

Arts, W., and J. Gelissen. 2002. Three worlds of welfare capitalism or more? Journal of European Social Policy 12 (2):137-158.

Avineri S and de Shalit A (1992) Introduction. In Avineri S and de Shalit A (Eds)

Communitarianism and Individualism. Oxford: Oxford University Press.

Borrell C, Espelt A, Rodríguez-Sanz M, Navarro V (2007) Politics and health. Journal of Epidemiology and Community Health 61 658-659.

Broome J (1991) Weighing Goods. Oxford: Blackwell.

Burström K, Johannesson M, Diderichsen F (2005). Increasing socio-economic inequalities in life expectancy and QALYs in Sweden 1980-1997. Health Economics. 148 831-850.

Caney S, (1992). Liberalism and communitarianism - a misconceived debate, Political Studies 40 2:273-289.

Cavallo F (2006) Do welfare regimes mediate the effect of socioeconomic position on health in adolescence? A cross-national comparison in Europe, North America, and Israel. International Journal of Health Services 362 309-29.

Chung H, Muntaner C (2007) Welfare state matters: A typological multilevel analysis of wealthy countries. Health Policy 802 328-339.

Coast J (2004) Is economic evaluation in touch with society's health values? British Medical Journal 329 1233-1236.

Culyer AJ (1988) inequality of health services is, in general, desirable. In Green D (Ed) Acceptable Inequalities. London: IEA Health Unit.

Culyer AJ (1990) Demand-side socialism and health care. Keynote paper presented at the Second World Congress on Health Economics. Zurich: University of Zurich.

Det Etiske Råd (1996) Prioritering I sundhedsvaesenet - en redogörelse, Köbenhavn

Ecosystem Valuation. Methods Section 6 Contingent Valuation Method http://www.ecosystemvaluation.org/contingent valuation.htm\#issues (accessed 5 March 2012).

Eikemo TA, Huisman M, Bambra C and Kunst AE (2008) Health inequalities according to educational level in different welfare regimes: a comparison of 23 European countries. Sociology of Health and Illness $304565-82$.

Esping-Andersen G (1990) The Three Worlds of Welfare Capitalism. Princeton, NJ: Princeton University Press.

Ferrera M (1996) The 'Southern' model of welfare in social Europe. Journal of European Social Policy $6117-37$.

Gelbier S and Randall S (1982) Charles Edward Wallis and London's Schools of Dentistry. Medical History 26 395-404.

Gerdtham U-G and Johannesson M (2000) Income-Related Inequality in Life-Years and QualityAdjusted Life-Years in Sweden. Journal of Health Economics 19 1007-1026

Gusfield, J. R. (1975). The community: A critical response. New York: Harper Colophon. 
Helse-og omsorgsdepartementet (1987) Retningslinjer for prioriteringer innen norsk helsetjensete, NOU 198723.

Helse-og omsorgsdepartementet (1997). Prioritering på ny. Gjenomgang av retningslinjer for prioriteringer innen norsk helsetjensete, NOU 199718.

Hälso- och sjukvårdslag [The Health and Medical Service Act] 1982:763, 1997:142; SFS [Swedish Code of Statutes].

Hilson M (2008) The Nordic Model. Scandinavia since 1945. Great Britain: Reaktion Books.

Hurley J (1998) Welfarism, extra-welfarism and evaluative economic analysis in the health sector. In Barer ML, Getzen TE and Stoddart GL (Eds) Health, Health Care and Health Economics. Chichester: Wiley.

Katz A (2007) The Sach Report: Investing in health fro economic development - or increasing the size of the crumbs from the rich man's table? In Navarro V (Ed) Neoliberalism, Globalization and Inequalities. New York: Baywood.

Kunst A, Bos V, Lahelma E, et al (2005) Trends in socioeconomic inequalities in self-assessed health in 10 European countries. International Journal of Epidemiology 34 295-305.

Lewis J (1997) Gender and Welfare Regimes: Further Thoughts. Soc Pol 4(2): 160-177.

Lundberg O (2008) Commentary: politics and public health - some conceptual considerations concerning welfare state characteristics and public health outcomes. International Journal of Epidemiology 375 1105-8.

Mackenbach JP, Kunst A, Cavelaers AE, Groenhof F, Geurts JJ (1997) Socioeconomic inequalities in morbidity and mortality in western Europe. Lancet 349 1655-1659.

Mackenbach J, Bos V, Andersen O, et al. (2003). Widening socioeconomic inequalities in mortality in six western European countries. International Journal of Epidemiology 32 830-7.

Margolis H (1982) Selfishness, Altruism and Rationality. Cambridge: Cambridge University Press.

Marmot M et al (2010) Fair society, healthy lives. Strategic review of health inequalities in England post 2010 (Marmot Review).

McMillan, D.W., \& Chavis, D.M. (1986). Sense of community: A definition and theory. Journal of Community Psychology, 14(1), 6-23.

Ministry of Health and Social Affairs (1993) Health Care and Medical Priorities Commission. No easy choices - the difficult priorities of healthcare. Stockholm: Ministry of Health and Social Affairs 93.

Ministry of Health and Social Affairs (1997) Prioriteringar inom hälso- och sjukvård.: Prop(Government Bill): 1996/97 60.

Mooney G (2009) Challenging Health Economics. Oxford: Oxford University Press.

Mooney G (2010) Citizens' juries. Available at gavinmooney.com Accessed October 2011.

Mooney G and Russell E (2003) Equity in health care: the need for a new paradigm? In Scott A, Maynard A and Elliott R (Eds) Advances in Health Economics. Chichester: Wiley.

Mooney G and Ryan M (1993) Agency in health care: getting beyond first principles. Journal of Health Economics 122 125-135. 
Muntaner C, Borrell C, Ng E, Chung H, Espelt A, Rodriguez-Sanz M, Benach J and O'Campo, P (2011) Sociology of Health and Illness 336 946-964.

Navarro V (2002) (Ed) The Political Economy of Social Inequalities. New York: Baywood.

Navarro V (2007) (Ed) Neoliberalism, Globalization and Inequalities. New York: Baywood.

Navarro V, Muntaner C, Borrell C, Benach J, Quiroga A, Rodríguez- Sanz M, Vergés N,

Pasarínet MI (2006). Politics and health outcomes. Lancet 368 1033-1037.

Olsen JA (1997) Aiding priority setting in health care: is there a role for the contingent valuation method? Health Economics 66 603-612.

Richardson J (2001) Empirical ethics: or the poverty of ethical analyses in economics and the unwarranted disregard of evidence in ethics. Working Paper 120. Melbourne: Centre for Health Program Evaluation, Monash University.

Rosa H (1996) Cultural relativism and social criticism from a Taylorian perspective, Constellations 31 :st about to send it to you 39-60.

Sen A (1987) On ethics and economics. Oxford: Basil Blackwell

Sen A (1992) Inequality Re-Examined. Oxford: Clarendon Press.

Siaroff, A. (1994). Work, Welfare and Gender Equality: a New Typology

In Gendering Welfare States, edited by D. Sainsbury. London: Sage.

Spash CL (2008) The contingent valuation method: retrpospect and prospect. Socio-Economics and the Environment. CSIRO Working Paper Series 2008-04. Canberra: CSIRO

Vanberg VJ (1994) Rules and Choices in Economics. London: Routledge.

van Doorslaer, E., Wagstaff, A. et al (1997) Income-related inequalities in health: some international comparisons. Journal of Health Economics 16 93-112.

WHO (2001) Investing in Health for Economic Development. Report of the Commission on Macroeconomics and Health. Chaired by Jeffrey D. Sachs. Geneva: WHO.

Wilkinson R (2005) The Impact of Inequality. London: Routledge. 